\title{
Associations of preoperative serum high-density lipoprotein cholesterol and low-density lipoprotein cholesterol levels with the prognosis of ovarian cancer
}

\section{Qingqing Lin}

Affiliated Hangzhou First People's Hospital Zhejiang University School of Medicine: Hangzhou First People's Hospital https://orcid.org/0000-0001-6415-5579

Wenchao Liu

First Hospital of Zhejiang Province: Zhejiang University School of Medicine First Affiliated Hospital

\section{Song Xu}

Affiliated Hangzhou First People's Hospital Zhejiang University School of Medicine: Hangzhou First People's Hospital

\section{Liping Sun ( $\nabla 1250498627 @ q q . c o m$ )}

Zhejiang University School of Medicine

\section{Research}

Keywords: Ovarian cancer, High-density lipoprotein cholesterol, Low-density lipoprotein cholesterol, Prognosis

Posted Date: February 19th, 2021

DOI: https://doi.org/10.21203/rs.3.rs-210363/v1

License: (a) (i) This work is licensed under a Creative Commons Attribution 4.0 International License. Read Full License 


\section{Abstract \\ Background}

The effect of serum lipids on ovarian cancer is controversial. We conduct this study to evaluate the prognostic value of preoperative plasma lipid profile in patients with ovarian cancer.

\section{Methods}

The medical records of 156 epithelial ovarian cancer patients who underwent surgical resection in our department were retrospectively reviewed and analyzed. Serum lipids profiles, including total cholesterol (TC), high-density lipoprotein cholesterol (HDL-C), low-density lipoprotein cholesterol (LDL-C), triglyceride (TG), apolipoprotein $A-\mathbb{X}(a p o A-\mathbb{X})$, apolipoprotein $B(a p o B)$ and clinicopathologic data were analyzed. Cox proportional hazards regression analyses and Kaplan-Meier method were performed to evaluate the overall survival (OS) and progression-free survival (PFS).

\section{Results}

Multivariable Cox regression analysis found that preoperative higher LDL-C level was significantly associated with worse OS (HR 2.088, 95\% $\mathrm{Cl} 1.052-4.147, \mathrm{p}=0.035)$, whereas higher HDL-C level showed significant association with better PFS (HR 0.491, 95\% Cl 0.247-0.975, $p=0.042)$. Further Kaplan-Meier survival analysis demonstrated that OS was longer for patients with low levels of LDL-C $(<2.76 \mathrm{mmol} / \mathrm{L})$ compared to those with high levels of LDL-C $(\geq 2.76 \mathrm{mmol} / \mathrm{L})(P=0.028)$, and PFS was better for patients with high levels of HDL-C $(\geq 1.19 \mathrm{mmol} / \mathrm{L})$ compared to those with low levels of HDL-C $(<1.19$ $\mathrm{mmol} / \mathrm{L})(\mathrm{P}=0.001)$.

\section{Conclusions}

Preoperative HDL-C and LDL-C levels are significant predictors of clinical outcome in patients with epithelial ovarian cancer.

\section{Background}

Epithelial ovarian cancer (EOC) is the most lethal gynecological malignancy [1]. Annually worldwide, 230000 women will be diagnosed and 150000 will die [2]. The standard treatment for EOC is primary surgery followed by the combination of platinum and taxane chemotherapy [3]. Recently, weekly paclitaxel therapy, intraperitoneal chemotherapy, and bevacizumab therapy are also considered to be acceptable as primary therapy [4-7]. However, owing to late diagnosis with advanced-stage disease, up to $80 \%$ of the patients have a relapse within five years, and the overall survival remains poor [8]. Thus, it is important to search for effective and accessible prognostic factors to identify ovarian cancer. 
In the last decade, dysregulation of lipid metabolism has been increasingly recognized as a component of malignant transformation in many different cancers, including ovarian cancer $[9,10]$. Lipids, as a kind of vital metabolites, comprise the majority of cellular membranes, play important roles as signaling molecules and contribute significantly to energy [11]. In order to fulfill the increased biochemical demands that accompany increased proliferation, lipid metabolism is often dysregulated in cancer [12]. The metabolic reprogramming is now understood to be linked to rapid growth of tumors, metastatic potential, resistance to chemotherapy, and cancer stemness [11]. Accordingly, altered metabolism has now been added to the list of cancer hallmarks [13].

Variations of plasma lipids and lipoproteins have been observed in ovarian cancer patients. Several studies have investigated whether the unbalanced lipid profile is associated with risk of developing ovarian cancer. Helzlsouer et al. [14] reported that women with a higher serum cholesterol level had an increased risk of ovarian cancer. A study by Delimaris et al. [15] found that oxidized low-density lipoprotein (ox-LDL) in serum was higher in ovarian cancer patients than in control subjects, but total cholesterol (TC) and high-density lipoprotein (HDL) showed no such association. Moreover, a recent study has clarified that elevated triglycerides (TG) was linked with cancer risk in patients with EOC [16]. In addition, it has been suggested that low levels of HDL could be reflective of an unfavorable hormonal profile which, in turn, would increase the risk of ovarian cancer [17].

However, the prognostic significance of lipid components in patients with EOC remains poorly understood. Therefore, in this study, we aimed to investigate the prognostic value of serum lipids and lipoproteins including TC, TG, high-density lipoprotein cholesterol (HDL-C), low-density lipoprotein

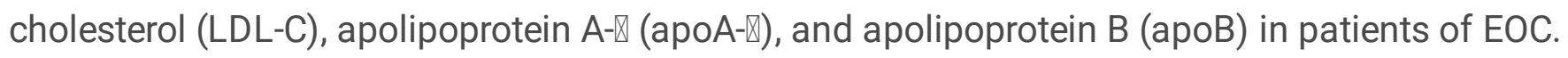

\section{Methods}

\section{Patient selection and clinical data collection}

This was a retrospective study of 156 patients with primary epithelial ovarian cancer treated at Hangzhou First People's Hospital between January 2009 and November 2015. The study was approved by the ethics committee of our hospital. All patients were eligible for inclusion in the study: (1) had undergone primary surgery aimed at complete resection of all visible tumor followed by at least six cycles of platinum-taxane combination chemotherapy; (2) had a histologically confirmed diagnosis of epithelial ovarian cancer; (3) without hormone replacement therapy or any other drugs known to affect lipid metabolism; (4) without cancer history; (5) serum samples (including total cholesterol (TC), triglycerides (TG), high-density lipoprotein cholesterol (HDL-C), low-density lipoprotein cholesterol (LDL-C), apolipoprotein A- $($ (apoA- $-\mathbb{X})$, and apolipoprotein $B(a p o B)$ ) were collected before treatment. Meanwhile, patient clinical characteristics including age, menopausal status, FIGO (International Federation of Gynecology and Obstetrics) stage, tumor histology and grade, lymph node metastatic status, initial level of cancer antigen 125 (CA-125), treatment (surgery, chemotherapy), recurrence, and death were collected. Optimal surgery was defined as residual tumor $<1 \mathrm{~cm}$. 


\section{Follow up}

All patients were followed up by medical records review and telephone interview. Data were collected until death or November 2020. Overall survival (OS), the primary endpoint of this study, was defined as the time from the date of primary cytoreductive surgery to the date of the last recorded clinical visit or death from any cause. Progression-free survival (PFS) was the secondary end point which was defined as the time interval from surgery to the date of disease recurrence or progression or the last follow-up.

\section{Statistical analysis}

Baseline characteristics of patient data were expressed as numbers and percentages for categorical variables. The cutoff value to stratify patients at high risk of death for serum TC, TG, HDL-C, LDL-C, apoA$\mathbb{Q}$, apoB and CA-125 was established by receiver operating characteristic (ROC) curves. To evaluate prognostic factors for PFS and OS, we did univariate and multivariate Cox proportional hazards regression analyses. All factors with $p$-value of $<0.1$ at univariate analyses were entered into a multivariate model, and hazard ratios (HRs) were calculated with $95 \%$ confidence intervals (Cls). The survival curves were explored through the Kaplan-Meier method with a log-rank test. All statistical analyses were performed using SPSS Statistics software (Version 20.0, Chicago, IL), and a p-value of less than 0.05 was considered statistically significant.

\section{Results}

\section{Characteristics of study patients}

A total of 156 patients were included in the analysis, and the median follow-up period was 82.2 months (range, 0.5 to 141.6 months). The baseline characteristics of these patients are summarized in Table 1. Their median age at diagnosis was 53 years (range, 15 to 87 years), and $69(44.2 \%)$ patients were premenopausal. Regarding the FIGO stage of disease, 46 (29.5\%), 19 (12.2\%), 79 (50.6) and 12 (7.7\%)

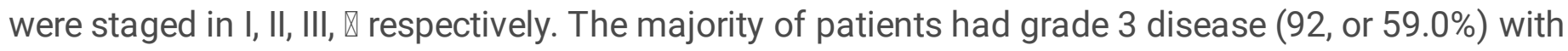
papillary serous histology (89, or $57.1 \%$ ). Median CA-125 level was $275.3 \mathrm{kU} / \mathrm{L}$ (range, 5.3 to $10000 \mathrm{kU} / \mathrm{L}$ ) in all patients, and 68 (43.6\%) of them had lymph node metastasis. One hundred and thirty-seven patients (87.8\%) underwent optimal cytoreductive surgery at initial exploration to residual disease less than $1 \mathrm{~cm}$. Further descriptive data were shown in Table 1. 
Table 1

Characteristics of all patients $(n=156)$

\begin{tabular}{|c|c|c|}
\hline Characteristic & Patients & $\%$ \\
\hline \multicolumn{3}{|l|}{ Age (years) } \\
\hline$<50$ & 66 & 42.3 \\
\hline$\geq 50$ & 90 & 57.7 \\
\hline \multicolumn{3}{|c|}{ Menopausal status } \\
\hline Premenopause & 69 & 44.2 \\
\hline Menopause & 87 & 55.8 \\
\hline \multicolumn{3}{|l|}{ Stage } \\
\hline I & 46 & 29.5 \\
\hline II & 19 & 12.2 \\
\hline III & 79 & 50.6 \\
\hline$\square$ & 12 & 7.7 \\
\hline \multicolumn{3}{|l|}{ Grade } \\
\hline 1 & 31 & 19.9 \\
\hline 2 & 33 & 21.2 \\
\hline 3 & 92 & 59.0 \\
\hline \multicolumn{3}{|l|}{ Histology } \\
\hline Serous & 89 & 57.1 \\
\hline Non-serous & 67 & 42.9 \\
\hline \multicolumn{3}{|c|}{ Lymph node metastasis } \\
\hline Present & 68 & 43.6 \\
\hline Absent & 88 & 56.4 \\
\hline \multicolumn{3}{|c|}{ Debulking operation } \\
\hline Optimal & 137 & 87.8 \\
\hline Suboptimal & 19 & 12.2 \\
\hline
\end{tabular}

CA-125: cancer antigen 125; HDL-C: high-density lipoprotein cholesterol; LDL-C: low-density lipoprotein cholesterol; ApoA囚: apolipoprotein A-邓; ApoB: apolipoprotein B. 


\begin{tabular}{|c|c|c|}
\hline Characteristic & Patients & $\%$ \\
\hline$<95.2$ & 65 & 41.7 \\
\hline$\geq 95.2$ & 91 & 58.3 \\
\hline \multicolumn{3}{|c|}{ Total cholesterol (mmol/L) } \\
\hline$<4.86$ & 86 & 55.1 \\
\hline$\geq 4.86$ & 70 & 44.9 \\
\hline \multicolumn{3}{|c|}{ Triglycerides (mmol/L) } \\
\hline$<1.36$ & 94 & 60.3 \\
\hline$\geq 1.36$ & 62 & 39.7 \\
\hline \multicolumn{3}{|c|}{$\mathrm{HDL}-\mathrm{C}(\mathrm{mmol} / \mathrm{L})$} \\
\hline$<1.19$ & 76 & 48.7 \\
\hline$\geq 1.19$ & 80 & 51.3 \\
\hline \multicolumn{3}{|c|}{ LDL-C (mmol/L) } \\
\hline$<2.76$ & 96 & 61.5 \\
\hline$\geq 2.76$ & 60 & 38.5 \\
\hline \multicolumn{3}{|l|}{ ApoA囚 (g/L) } \\
\hline$<1.51$ & 101 & 64.7 \\
\hline$\geq 1.51$ & 55 & 35.3 \\
\hline \multicolumn{3}{|l|}{ ApoB (g/L) } \\
\hline$<1.01$ & 78 & 50.0 \\
\hline$\geq 1.01$ & 78 & 50.0 \\
\hline
\end{tabular}

\section{Cut-off determination of serum lipid and lipoproteins}

ROC curves analysis showed that the optimal cutoff value of joint maximum sensitivity and specificity were for TC $4.86 \mathrm{mmol} / \mathrm{L}$ (AUC: $0.563,95 \% \mathrm{Cl}$ : $0.468-0.658$ ), $1.36 \mathrm{mmol} / \mathrm{L}$ for TG (AUC: $0.538,95 \% \mathrm{Cl}$ : $0.447-0.629), 1.19 \mathrm{mmol} / \mathrm{L}$ for HDL-C (AUC: $0.624,95 \% \mathrm{Cl}: 0.533-0.716)$, and $2.76 \mathrm{mmol} / \mathrm{L}$ for LDL-C

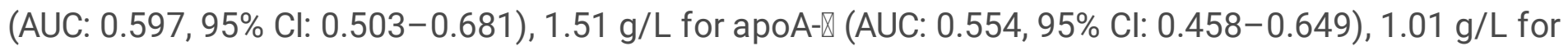
apoB (AUC: $0.508,95 \%$ Cl: 0.413-0.602), respectively.

\section{The prognostic impact of serum lipids on OS and PFS}




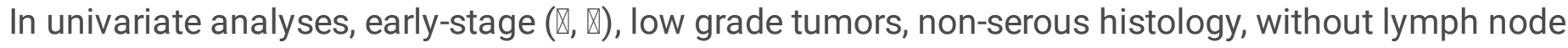
metastasis, preoperative lower CA125 and optimal debulking (residual disease $<1 \mathrm{~cm}$ ) were favorable prognostic factors for OS and PFS. Moreover, according to the recommended cutoff levels of preoperative serum lipids and lipoproteins, the preoperative higher TC, HDL-C, apoA- $\$ and lower LDL-C level were significantly associated with better OS and PFS (Tables 2 and 3).

Table 2

Univariable and multivariable Cox proportional hazards regression analyses of prognostic factors for OS

\begin{tabular}{|c|c|c|c|c|}
\hline \multirow[t]{2}{*}{ Factors } & \multicolumn{2}{|l|}{ Univariable analysis } & \multicolumn{2}{|c|}{ Multivariable analysis } \\
\hline & $\mathrm{HR}(95 \% \mathrm{Cl})$ & $\begin{array}{l}\mathrm{p} \\
\text { value }\end{array}$ & $\mathrm{HR}(95 \% \mathrm{Cl})$ & $\begin{array}{l}\mathrm{p} \\
\text { value }\end{array}$ \\
\hline Age $(\geq 50$ year vs. $<50$ year $)$ & $1.225(0.698-2.149)$ & 0.480 & & \\
\hline Menopause (yes vs. no) & $1.225(0.701-2.140)$ & 0.476 & & \\
\hline Stage (III, $\nabla$ vs. I, II) & $3.693(2.436-5.601)$ & $<.001$ & $\begin{array}{l}2.005(1.057- \\
3.805)\end{array}$ & 0.033 \\
\hline Grade (1, 2 vs. 3$)$ & $0.445(0.275-0.718)$ & 0.001 & $\begin{array}{l}0.738(0.428- \\
1.272)\end{array}$ & 0.274 \\
\hline Histology (Non-serous vs. Serous) & $0.281(0.140-0.562)$ & $<.001$ & $\begin{array}{l}0.593(0.262- \\
1.342)\end{array}$ & 0.210 \\
\hline $\begin{array}{l}\text { Lymph node metastasis (yes vs. } \\
\text { no) }\end{array}$ & $\begin{array}{l}8.959(4.342- \\
18.484)\end{array}$ & $<.001$ & $\begin{array}{l}2.515(1.078- \\
5.871)\end{array}$ & 0.033 \\
\hline Optimal debulking (no vs. yes) & $\begin{array}{l}9.810(5.294- \\
18.178)\end{array}$ & $<.001$ & $\begin{array}{l}3.913(1.925- \\
7.956)\end{array}$ & $\stackrel{<}{<.001}$ \\
\hline $\mathrm{CA} 125 \geq 95.2 \mathrm{kU} / \mathrm{L}$ & $4.694(2.204-9.997)$ & $<.001$ & $\begin{array}{l}1.139(0.496- \\
2.612)\end{array}$ & 0.759 \\
\hline Total cholesterol $\geq 4.86 \mathrm{mmol} / \mathrm{L}$ & $0.526(0.293-0.943)$ & 0.031 & $\begin{array}{l}0.556(0.266- \\
1.164)\end{array}$ & 0.119 \\
\hline Triglycerides $\geq 1.36 \mathrm{mmol} / \mathrm{L}$ & $1.052(0.602-1.838)$ & 0.860 & & \\
\hline $\mathrm{HDL}-\mathrm{C} \geq 1.19 \mathrm{mmol} / \mathrm{L}$ & $0.298(0.161-0.551)$ & $<.001$ & $\begin{array}{l}0.586(0.257- \\
1.339)\end{array}$ & 0.205 \\
\hline LDL-C $\geq 2.76 \mathrm{mmol} / \mathrm{L}$ & $1.835(1.059-3.180)$ & 0.030 & $\begin{array}{l}2.088(1.052- \\
4.147)\end{array}$ & 0.035 \\
\hline ApoA I $\geq 1.51 \mathrm{~g} / \mathrm{L}$ & $0.515(0.270-0.985)$ & 0.045 & $\begin{array}{l}1.282(0.550- \\
2.988)\end{array}$ & 0.566 \\
\hline$A p o B \geq 1.01 \mathrm{~g} / \mathrm{L}$ & $0.747(0.430-1.298)$ & 0.301 & & \\
\hline
\end{tabular}


Table 3

Univariable and Multivariable Cox proportional hazards regression analyses of prognostic factors for PFS

\begin{tabular}{|c|c|c|c|c|}
\hline \multirow[t]{2}{*}{ Factors } & \multicolumn{2}{|l|}{ Univariable analysis } & \multicolumn{2}{|c|}{ Multivariable analysis } \\
\hline & $\mathrm{HR}(95 \% \mathrm{Cl})$ & $\begin{array}{l}\mathrm{p} \\
\text { value }\end{array}$ & $\mathrm{HR}(95 \% \mathrm{Cl})$ & $\begin{array}{l}\mathrm{p} \\
\text { value }\end{array}$ \\
\hline Age ( $\geq 50$ year vs. $<50$ year) & $1.471(0.902-2.400)$ & 0.122 & & \\
\hline Menopause (yes vs. no) & $1.417(0.876-2.294)$ & 0.156 & & \\
\hline 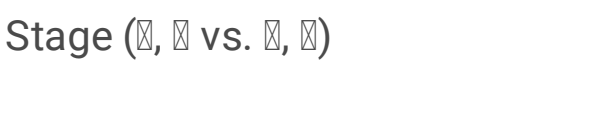 & $3.315(2.398-4.583)$ & $<.001$ & $\begin{array}{l}1.939(1.209- \\
3.111)\end{array}$ & 0.006 \\
\hline Grade (1, 2 vs. 3$)$ & $0.459(0.310-0.679)$ & 0.001 & $\begin{array}{l}0.795(0.510- \\
1.239)\end{array}$ & 0.311 \\
\hline $\begin{array}{l}\text { Histology (Non-serous vs. } \\
\text { Serous) }\end{array}$ & $0.314(0.179-0.550)$ & $<.001$ & $\begin{array}{l}0.577(0.306- \\
1.090)\end{array}$ & 0.090 \\
\hline $\begin{array}{l}\text { Lymph node metastasis (yes vs. } \\
\text { no) }\end{array}$ & $\begin{array}{l}6.814(3.914- \\
11.864)\end{array}$ & $<.001$ & $\begin{array}{l}1.726(0.866- \\
3.439)\end{array}$ & 0.121 \\
\hline Optimal debulking (no vs. yes) & $\begin{array}{l}12.431(6.916- \\
22.343)\end{array}$ & $<.001$ & $\begin{array}{l}4.465(2.206- \\
9.037)\end{array}$ & $\dot{L}_{0.001}$ \\
\hline CA125 $\geq 95.2 \mathrm{kU} / \mathrm{L}$ & $4.225(2.308-7.736)$ & $<.001$ & $\begin{array}{l}1.233(0.625- \\
2.434)\end{array}$ & 0.546 \\
\hline Total cholesterol $\geq 4.86 \mathrm{mmol} / \mathrm{L}$ & $0.536(0.327-0.878)$ & 0.013 & $\begin{array}{l}0.768(0.399- \\
1.481)\end{array}$ & 0.431 \\
\hline Triglycerides $\geq 1.36 \mathrm{mmol} / \mathrm{L}$ & $1.068(0.664-1.720)$ & 0.786 & & \\
\hline $\mathrm{HDL}-\mathrm{C} \geq 1.19 \mathrm{mmol} / \mathrm{L}$ & $0.279(0.165-0.470)$ & $<.001$ & $\begin{array}{l}0.491(0.247- \\
0.975)\end{array}$ & 0.042 \\
\hline LDL-C $\geq 2.76 \mathrm{mmol} / \mathrm{L}$ & $1.624(1.015-2.597)$ & 0.043 & $\begin{array}{l}1.805(0.991- \\
3.288)\end{array}$ & 0.054 \\
\hline $\mathrm{ApoA} \varangle \geq 1.51 \mathrm{~g} / \mathrm{L}$ & $0.471(0.270-0.824)$ & 0.008 & $\begin{array}{l}1.053(0.520- \\
2.133)\end{array}$ & 0.886 \\
\hline$A p o B \geq 1.01 \mathrm{~g} / \mathrm{L}$ & $0.916(0.573-1.465)$ & 0.715 & & \\
\hline
\end{tabular}

In multivariate analyses, early-stage, without lymph node metastasis and optimal debulking remained as favorable prognostic factors for OS. Early-stage and optimal debulking predicted longer PFS. The HRs of OS were $2.005(95 \% \mathrm{Cl} 1.057-3.805, \mathrm{p}=0.033)$ for advanced FIGO stage, $2.515(95 \% \mathrm{Cl} 1.078-5.871, \mathrm{p}=$ 0.033) for lymph node metastasis, and $3.913(95 \% \mathrm{Cl} 1.925-7.956, \mathrm{p}<0.001)$ for suboptimal debulking, while the HRs of PFS were $1.939(95 \% \mathrm{Cl} 1.209-3.111, \mathrm{p}=0.006)$ for advanced FIGO stage and 4.465 
$(95 \% \mathrm{Cl} 2.206-9.037, \mathrm{p}<0.001)$ for suboptimal debulking. Furthermore, the results revealed that preoperative higher LDL-C level was significantly associated with worse OS (HR 2.088, 95\% Cl 1.0524.147, $p=0.035$ ), whereas higher HDL-C level showed significant association with better PFS (HR 0.491, $95 \% \mathrm{Cl} 0.247-0.975, \mathrm{p}=0.042$ ) (Tables 2 and 3 ).

\section{Kaplan-Meier curves analyses of HDL-C and LDL-C}

Kaplan-Meier curves with log-rank tests stratified by the cutoff value level of LDL-C and HDL-C were performed to assess the prognostic significance of the serum lipid profile in ovarian cancer. It demonstrated that the patients with high levels of HDL-C $(\geq 1.19 \mathrm{mmol} / \mathrm{L})$ had a better PFS compared with those with low levels of HDL-C $(<1.19 \mathrm{mmol} / \mathrm{L})(P=0.001)$ (Fig. 1), whereas the patients with low levels of LDL-C $(<2.76 \mathrm{mmol} / \mathrm{L})$ had a better OS compared with those with high levels of LDL-C $(\geq 2.76$ $\mathrm{mmol} / \mathrm{L})(\mathrm{P}=0.028)$ (Fig. 2).

\section{Discussion}

Study of the relationship between ovarian cancer and serum lipid levels, including TC, TG, HDL-C, LDL-C, and apolipoproteins, is of special interest and has sparked debate, and no consensus of their significance has been established. The aim of the present study was to evaluate the association between lipid profiles and ovarian cancer. We found that high level of preoperative HDL-C was a significant independent predictor of better PFS in ovarian cancer patients, whereas high level of LDL-C showed significant association with worse OS.

Cancer cells show specific alterations in different aspects of lipid metabolism, which are related to important cellular processes, including cell growth, proliferation, differentiation, and motility [18]. As the primary mediators of cholesterol and lipid transport, lipoproteins are essential components of energy and lipid metabolism in the body, which may have direct effects on carcinogenesis. Some observational studies have indicated a relationship between HDL-C levels with some cancer types [19-23].

Epidemiological data have shown levels of HDL-C are significantly inversely associated with risk for multiple cancers [24-26]. The meta-analysis conducted by D. Zhang et al. [27] revealed an association between high HDL-C levels and lower ovarian cancer risk. Two retrospective studies also showed that low HDL-C levels were strongly correlated with severity of epithelial ovarian cancer [20,28]. Although a metaanalysis including 25 studies with a total of 13,140 patients indicated that high serum HDL-C levels were associated with better OS and PFS in most of tumor types [29], the association between HDL-C and ovarian cancer still remains unclear. In our study, we have observed that patients with HDL-C level $\geq 1.19$ $\mathrm{mmol} / \mathrm{L}$ had a better PFS than patients with HDL-C level $<1.19 \mathrm{mmol} / \mathrm{L}(p=0.001)$. HDLs play a key role in the reverse cholesterol transport (RCT), which can promote cholesterol removal from cancer cells, thus altering their homeostasis [30]. In addition, HDLs are able to affect several other pathways, including oxidation, inflammation, apoptosis, angiogenesis and immunomodulatory activities which may be also relevant for cancer biology. The anti-oxidative properties of HDLs have been linked to their capacity to protect LDL from oxidative modification, which might be facilitated by HDL-associated apolipoproteins and enzymes, such as apoA囚, apoE2, apoA囚, apoJ, PON1 and LCAT [31-33]. Besides, HDLs are able to 
prevent the release of proinflammatory cytokines and to upregulate the expression of endothelial and leukocyte adhesion molecules, thus exerting anti-inflammatory effects. In addition, the anti-apoptotic effects of HDLs can be attributed to their ability to interact with caspase-3, a key factor of apoptotic pathway, or to induce upregulation of the anti-apoptotic $\mathrm{Bcl}-2$ protein $\mathrm{Bcl}-\mathrm{xL}[34,35]$. The pleiotropic activities of HDLs result into an overall anti-tumorigenesis effects.

Concerning LDL-C, discordant results were also found. One retrospective study from the United States showed that OS and PFS were longer for patients with normal LDL levels compared to those with elevated LDL, and LDL was suggested as a predictor of clinical outcome [36]. In contrast, another retrospective study by Zhu et al [37] found that high levels of LDL was associated with a better recurrence-free survival in women with ovarian cancer. It should also be noted that a Mendelian randomization study of 22,406 women with ovarian cancer did not find any association between genetic variation in controlling LDL-C and risk of epithelial ovarian cancer [38]. In this study, we found that patients with LDL-C level $<2.76 \mathrm{mmol} / \mathrm{L}$ had better OS than patients with LDL-C level $\geq 2.76 \mathrm{mmol} / \mathrm{L}(\mathrm{P}=$ 0.028). As a main cholesterol transporter, LDL-C can provide cancer cells with lipids and cholesterol as a component for their proliferation. It was demonstrated that increased LDL receptor expressed in breast cancer tissue to increase the uptake of LDL-C from the bloodstream [39], and LDL promotes breast cancer progression by inducing cell proliferation, migration and loss of adhesion [40,41]. However, the proliferation rates of ovarian carcinoma cell lines CAOV3 and SKOV3 remained unchanged when they were treated with LDL, which was stimulated by oxidized low-density lipoprotein (ox-LDL), accompanied by an induction of the expression of the antiapoptotic cytokine cardiotrophin 1 [42]. Besides, it was found that ovarian cancer patients possessed high levels of ox-LDL compared with control subjects [15], which indicated that ox-LDL has an important role in ovarian cancer development. The oxidation of LDL results in the formation of peroxidation metabolites which cause structural alterations in DNA and decrease DNA repair capacity through their direct interaction with repair enzymes [43]. Studies have showed a positive correlation between increased serum ox-LDL levels and an increased risk of colon, breast, and ovarian cancer [44-46]. Ox-LDL and its receptor LOX-1 activate the inflammatory pathway through nuclear factorkappa B, leading to cell transformation. LOX-1 is important for maintaining the transformed state in developmentally diverse cancer cell lines and for tumor growth [49]. However, the studies remained limited, detailed mechanisms of LDL need further investigation.

Several limitations of our study should be considered. Firstly, this was a retrospective study, and patients were excluded if data on serum lipid levels were not available. This may have caused selection bias. Secondly, serum lipid levels were measured only once before treatment, but they may change over time depending on the patient's clinical course and disease status. Thirdly, the cohort of our study was relatively small and from a single center, further multi-center studies with more cases may be needed to minimize selection bias and potential confounding factors such as difference in geographic distribution. Despite these limitations, the use of Cox proportional hazards regression to perform a multivariate analysis is relative strengths of our study. 


\section{Conclusion}

In conclusion, our results provide evidence that HDL-C and LDL-C levels at diagnosis may be independent prognostic factors for epithelial ovarian cancer, suggesting that serum lipid levels may be used as predictive factors for screening and follow-up of ovarian cancer. In addition, it may be beneficial to adjust these parameters with appropriate therapies in addition to routine cancer therapies. More multiple center and prospective studies are needed.

\section{Abbreviations}

TC

total cholesterol

HDL-C

high-density lipoprotein cholesterol

\section{LDL-C}

low-density lipoprotein cholesterol

TG

triglyceride

ApoA-I

apolipoprotein A-I

ApoB

apolipoprotein B

OS

overall survival

PFS

progression-free survival

EOC

epithelial ovarian cancer

Ox-LDL

oxidized low-density lipoprotein

HDL

high-density lipoprotein

FIGO

International Federation of Gynecology and Obstetrics

CA-125

cancer antigen 125

ROC

receiver operating characteristic

HR

hazard ratio 
confidence intervals

RCT

reverse cholesterol transport

\section{Declarations}

\section{Ethics approval and consent to participate}

The study was compliant with the Declaration of Helsinki, and approved by the Ethics Committee of Affiliated Hangzhou First People's Hospital of Zhejiang University. Informed consent was waived due to its retrospective nature.

\section{Consent for publication}

Informed consent was obtained from all individual participants included in the study.

\section{Availability of data and materials}

All data generated or analyzed during this study are included in this published article.

\section{Competing interests}

The authors declare that they have no competing interests

\section{Funding}

The present study was supported by grants from the Medical Scientific Research Foundation of Zhejiang Province, China (2021RC100). The sponsor had no role in the design or conduct of this research.

\section{Authors' contributions}

LPS and QQL conceived and designed the experiments. QQL and SX extracted and analyzed data. QQL and WCL were the statisticians who confirmed the analysis of this study. QQL and WCL wrote the manuscript. All authors read and approved the final manuscript.

\section{Acknowledgements}

Not applicable.

\section{Authors' information}

\section{Affiliations}

Department of Gynecology, Affiliated Hangzhou First People's Hospital, Zhejiang University School of Medicine, Hangzhou, Zhejiang, 310006, China 
Qingqing Lin, Song Xu, \& Liping Sun

Department of Neurosurgery, First Affiliated Hospital, School of Medicine, Zhejiang University, Hangzhou, Zhejiang, 310003, China

Wenchao Liu

Corresponding authors

Correspondence to Liping Sun and Song Xu

\section{References}

1. Ferlay J, Colombet M, Soerjomataram I, Mathers C, Parkin DM, Pineros M, Znaor A, Bray F:

Estimating the global cancer incidence and mortality in 2018: GLOBOCAN sources and methods. International journal of cancer 2019, 144(8):1941-1953.

2. Bray F, Ferlay J, Soerjomataram I, Siegel RL, Torre LA, Jemal A: Global cancer statistics 2018: GLOBOCAN estimates of incidence and mortality worldwide for 36 cancers in 185 countries. CA: a cancer journal for clinicians 2018, 68(6):394-424.

3. Piver MS: Treatment of ovarian cancer at the crossroads: $\mathbf{5 0}$ years after single-agent melphalan chemotherapy. Oncology 2006, 20(10):1156, 1158.

4. Katsumata N, Yasuda M, Isonishi S, Takahashi F, Michimae H, Kimura E, Aoki D, Jobo T, Kodama S, Terauchi $\mathrm{F}$ et al: Long-term results of dose-dense paclitaxel and carboplatin versus conventional paclitaxel and carboplatin for treatment of advanced epithelial ovarian, fallopian tube, or primary peritoneal cancer (JGOG 3016): a randomised, controlled, open-label trial. The Lancet Oncology 2013, 14(10):1020-1026.

5. Perren TJ, Swart AM, Pfisterer J, Ledermann JA, Pujade-Lauraine E, Kristensen G, Carey MS, Beale P, Cervantes A, Kurzeder $\mathrm{C}$ et al: A phase 3 trial of bevacizumab in ovarian cancer. The New England journal of medicine 2011, 365(26):2484-2496.

6. Burger RA, Brady MF, Bookman MA, Fleming GF, Monk BJ, Huang H, Mannel RS, Homesley HD, Fowler J, Greer BE et al: Incorporation of bevacizumab in the primary treatment of ovarian cancer. The New England journal of medicine 2011, 365(26):2473-2483.

7. Armstrong DK, Bundy B, Wenzel L, Huang HQ, Baergen R, Lele S, Copeland LJ, Walker JL, Burger RA, Gynecologic Oncology G: Intraperitoneal cisplatin and paclitaxel in ovarian cancer. The New England journal of medicine 2006, 354(1):34-43.

8. Mor G, Alvero A: The duplicitous origin of ovarian cancer. Rambam Maimonides medical journal 2013, 4(1):e0006.

9. Corbet C, Feron O: Emerging roles of lipid metabolism in cancer progression. Current opinion in clinical nutrition and metabolic care 2017, 20(4):254-260. 
10. Rohrig F, Schulze A: The multifaceted roles of fatty acid synthesis in cancer. Nature reviews Cancer 2016, 16(11):732-749.

11. Zhao G, Cardenas H, Matei D: Ovarian Cancer-Why Lipids Matter. Cancers 2019, 11(12).

12. Faubert B, Solmonson A, DeBerardinis RJ: Metabolic reprogramming and cancer progression. Science 2020, 368(6487).

13. Ward PS, Thompson CB: Metabolic reprogramming: a cancer hallmark even warburg did not anticipate. Cancer Cell 2012, 21(3):297-308.

14. Helzlsouer KJ, Alberg AJ, Norkus EP, Morris JS, Hoffman SC, Comstock GW: Prospective study of serum micronutrients and ovarian cancer. Journal of the National Cancer Institute 1996, 88(1):32-37.

15. Delimaris I, Faviou E, Antonakos G, Stathopoulou E, Zachari A, Dionyssiou-Asteriou A: Oxidized LDL, serum oxidizability and serum lipid levels in patients with breast or ovarian cancer. Clinical biochemistry 2007, 40(15):1129-1134.

16. Li J, Xie H, Li A, Cheng J, Yang K, Wang J, Wang W, Zhang F, Li Z, Dhillon HS et al: Distinct plasma lipids profiles of recurrent ovarian cancer by liquid chromatography-mass spectrometry. Oncotarget 2017, 8(29):46834-46845.

17. Tania M, Khan MA, Song Y: Association of lipid metabolism with ovarian cancer. Current oncology 2010, 17(5):6-11.

18. Santos CR, Schulze A: Lipid metabolism in cancer. The FEBS journal 2012, 279(15):2610-2623.

19. Nam SY, Park BJ, Nam JH, Kook MC: Effect of Helicobacter pylori eradication and high-density lipoprotein on the risk of de novo gastric cancer development. Gastrointestinal endoscopy 2019, 90(3):448-456 e441.

20. Li G, Zhang K, Gong F, Jin H: A study on changes and clinical significance of blood glucose, blood lipid and inflammation in patients with ovarian cancer. Journal of BUON : official journal of the Balkan Union of Oncology 2019, 24(6):2322-2326.

21. Stevanovic M, Vekic J, Bogavac-Stanojevic N, Janac J, Stjepanovic Z, Zeljkovic D, Trifunovic B, Spasojevic-Kalimanovska V, Zeljkovic A: Significance of LDL and HDL subclasses characterization in the assessment of risk for colorectal cancer development. Biochemia medica 2018, 28(3):030703.

22. Li X, Liu ZL, Wu YT, Wu H, Dai W, Arshad B, Xu Z, Li H, Wu KN, Kong LQ: Status of lipid and lipoprotein in female breast cancer patients at initial diagnosis and during chemotherapy. Lipids in health and disease 2018, 17(1):91.

23. Choi YJ, Lee DH, Han KD, Shin CM, Kim N: Abdominal obesity, glucose intolerance and decreased high-density lipoprotein cholesterol as components of the metabolic syndrome are associated with the development of colorectal cancer. European journal of epidemiology 2018, 33(11):1077-1085.

24. Mondul AM, Weinstein SJ, Virtamo J, Albanes D: Serum total and HDL cholesterol and risk of prostate cancer. Cancer causes \& control : CCC 2011, 22(11):1545-1552.

25. Ahn J, Lim U, Weinstein SJ, Schatzkin A, Hayes RB, Virtamo J, Albanes D: Prediagnostic total and high-density lipoprotein cholesterol and risk of cancer. Cancer epidemiology, biomarkers \& prevention 
: a publication of the American Association for Cancer Research, cosponsored by the American Society of Preventive Oncology 2009, 18(11):2814-2821.

26. Bayerdorffer E, Mannes GA, Richter WO, Ochsenkuhn T, Seeholzer G, Kopcke W, Wiebecke B, Paumgartner G: Decreased high-density lipoprotein cholesterol and increased low-density cholesterol levels in patients with colorectal adenomas. Annals of internal medicine 1993, 118(7):481-487.

27. Zhang D, Xi Y, Feng Y: Ovarian cancer risk in relation to blood lipid levels and hyperlipidemia: a systematic review and meta-analysis of observational epidemiologic studies. European journal of cancer prevention : the official journal of the European Cancer Prevention Organisation 2020.

28. Zhang Y, Wu J, Liang JY, Huang X, Xia L, Ma DW, Xu XY, Wu PP: Association of serum lipids and severity of epithelial ovarian cancer: an observational cohort study of 349 Chinese patients. Journal of biomedical research 2018, 32(5):336-342.

29. Hao B, Bi B, Sang C, Yu M, Di D, Luo G, Zhang X: Systematic Review and Meta-Analysis of the Prognostic Value of Serum High-Density Lipoprotein Cholesterol Levels for Solid Tumors. Nutrition and cancer 2019, 71(4):547-556.

30. Gomaraschi M: Role of Lipoproteins in the Microenvironment of Hormone-Dependent Cancers. Trends in endocrinology and metabolism: TEM 2020, 31(3):256-268.

31. Sacre SM, Stannard AK, Owen JS: Apolipoprotein E (apoE) isoforms differentially induce nitric oxide production in endothelial cells. FEBS letters 2003, 540(1-3):181-187.

32. Navab M, Hama SY, Cooke CJ, Anantharamaiah GM, Chaddha M, Jin L, Subbanagounder G, Faull KF, Reddy ST, Miller NE et al: Normal high density lipoprotein inhibits three steps in the formation of mildly oxidized low density lipoprotein: step 1. Journal of lipid research 2000, 41(9):1481-1494.

33. Heinecke JW: Oxidants and antioxidants in the pathogenesis of atherosclerosis: implications for the oxidized low density lipoprotein hypothesis. Atherosclerosis 1998, 141(1):1-15.

34. Riwanto M, Rohrer L, Roschitzki B, Besler C, Mocharla P, Mueller M, Perisa D, Heinrich K, Altwegg L, von Eckardstein A et al: Altered activation of endothelial anti- and proapoptotic pathways by highdensity lipoprotein from patients with coronary artery disease: role of high-density lipoproteinproteome remodeling. Circulation 2013, 127(8):891-904.

35. Sugano M, Tsuchida K, Makino N: High-density lipoproteins protect endothelial cells from tumor necrosis factor-alpha-induced apoptosis. Biochemical and biophysical research communications 2000, 272(3):872-876.

36. Li AJ, Elmore RG, Chen IY, Karlan BY: Serum low-density lipoprotein levels correlate with survival in advanced stage epithelial ovarian cancers. Gynecologic oncology 2010, 116(1):78-81.

37. Zhu F, Xu X, Shi B, Zeng L, Wang L, Wu X, Zhu H: The positive predictive value of low-density lipoprotein for recurrence-free survival in ovarian cancer. International journal of gynaecology and obstetrics: the official organ of the International Federation of Gynaecology and Obstetrics 2018, $143(2): 232-238$.

38. Yarmolinsky J, Bull CJ, Vincent EE, Robinson J, Walther A, Smith GD, Lewis SJ, Relton CL, Martin RM: Association Between Genetically Proxied Inhibition of HMG-CoA Reductase and Epithelial Ovarian 
Cancer. Jama 2020, 323(7):646-655.

39. Pires LA, Hegg R, Freitas FR, Tavares ER, Almeida CP, Baracat EC, Maranhao RC: Effect of neoadjuvant chemotherapy on low-density lipoprotein (LDL) receptor and LDL receptor-related protein 1 (LRP-1) receptor in locally advanced breast cancer. Brazilian journal of medical and biological research = Revista brasileira de pesquisas medicas e biologicas 2012, 45(6):557-564.

40. dos Santos CR, Domingues G, Matias I, Matos J, Fonseca I, de Almeida JM, Dias S: LDL-cholesterol signaling induces breast cancer proliferation and invasion. Lipids in health and disease 2014, 13:16.

41. Antalis CJ, Arnold T, Rasool T, Lee B, Buhman KK, Siddiqui RA: High ACAT1 expression in estrogen receptor negative basal-like breast cancer cells is associated with LDL-induced proliferation. Breast cancer research and treatment 2010, 122(3):661-670.

42. Scoles DR, Xu X, Wang H, Tran H, Taylor-Harding B, Li A, Karlan BY: Liver X receptor agonist inhibits proliferation of ovarian carcinoma cells stimulated by oxidized low density lipoprotein. Gynecologic oncology 2010, 116(1):109-116.

43. Wiseman $\mathrm{H}$, Halliwell $B$ : Damage to DNA by reactive oxygen and nitrogen species: role in inflammatory disease and progression to cancer. The Biochemical journal 1996, 313 (Pt 1):17-29.

44. Pischon T, Nothlings U, Boeing H: Obesity and cancer. The Proceedings of the Nutrition Society 2008, 67(2):128-145.

45. Mantovani A, Allavena P, Sica A, Balkwill F: Cancer-related inflammation. Nature 2008, 454(7203):436-444.

46. Giovannucci E: Metabolic syndrome, hyperinsulinemia, and colon cancer: a review. The American journal of clinical nutrition 2007, 86(3):s836-842.

47. Lu J, Mitra S, Wang X, Khaidakov M, Mehta JL: Oxidative stress and lectin-like ox-LDL-receptor LOX-1 in atherogenesis and tumorigenesis. Antioxidants \& redox signaling 2011, 15(8):2301-2333.

\section{Figures}




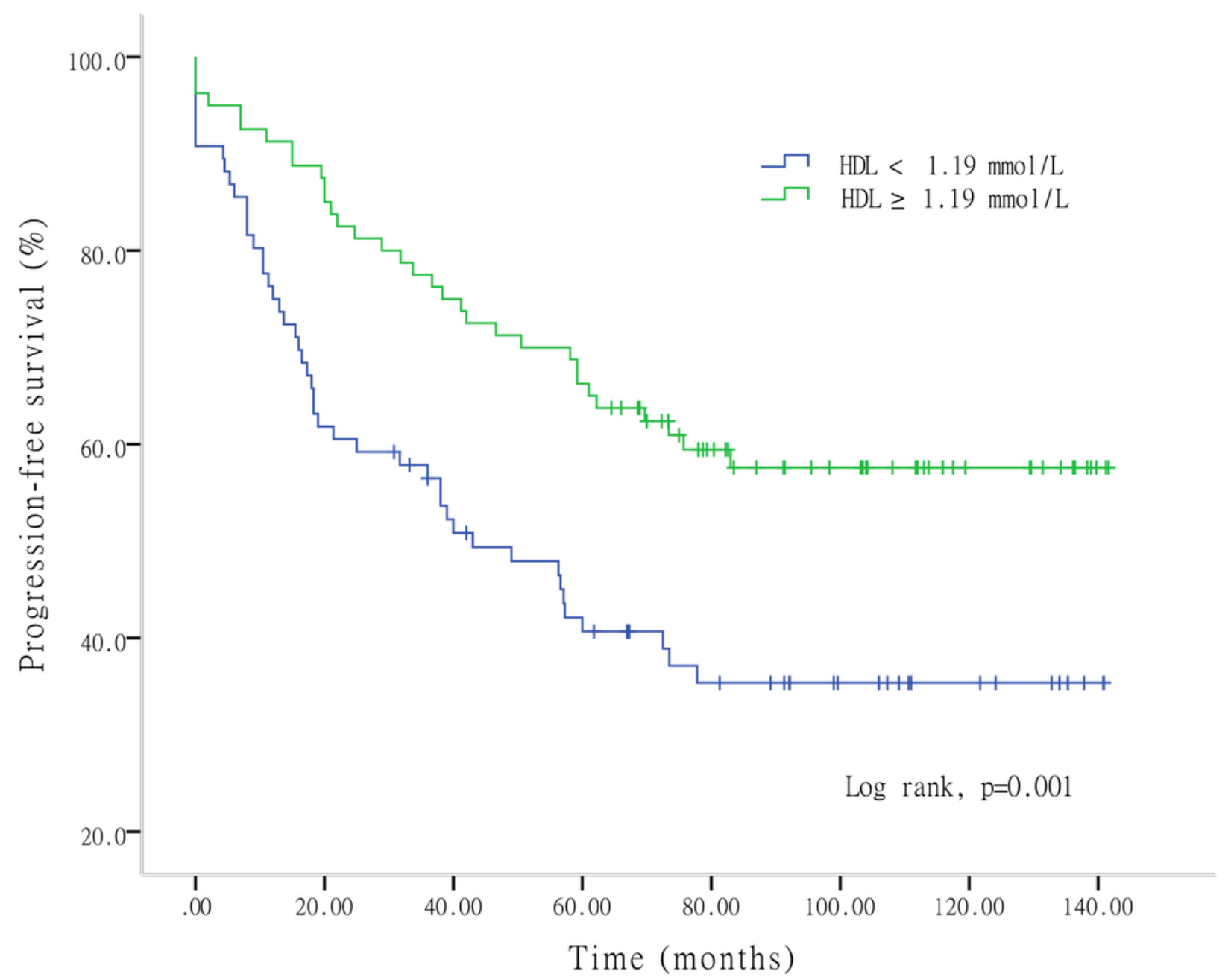

Figure 1

Kaplan-Meier curve of progression-free survival (PFS) according to low vs high HDL-C levels. 


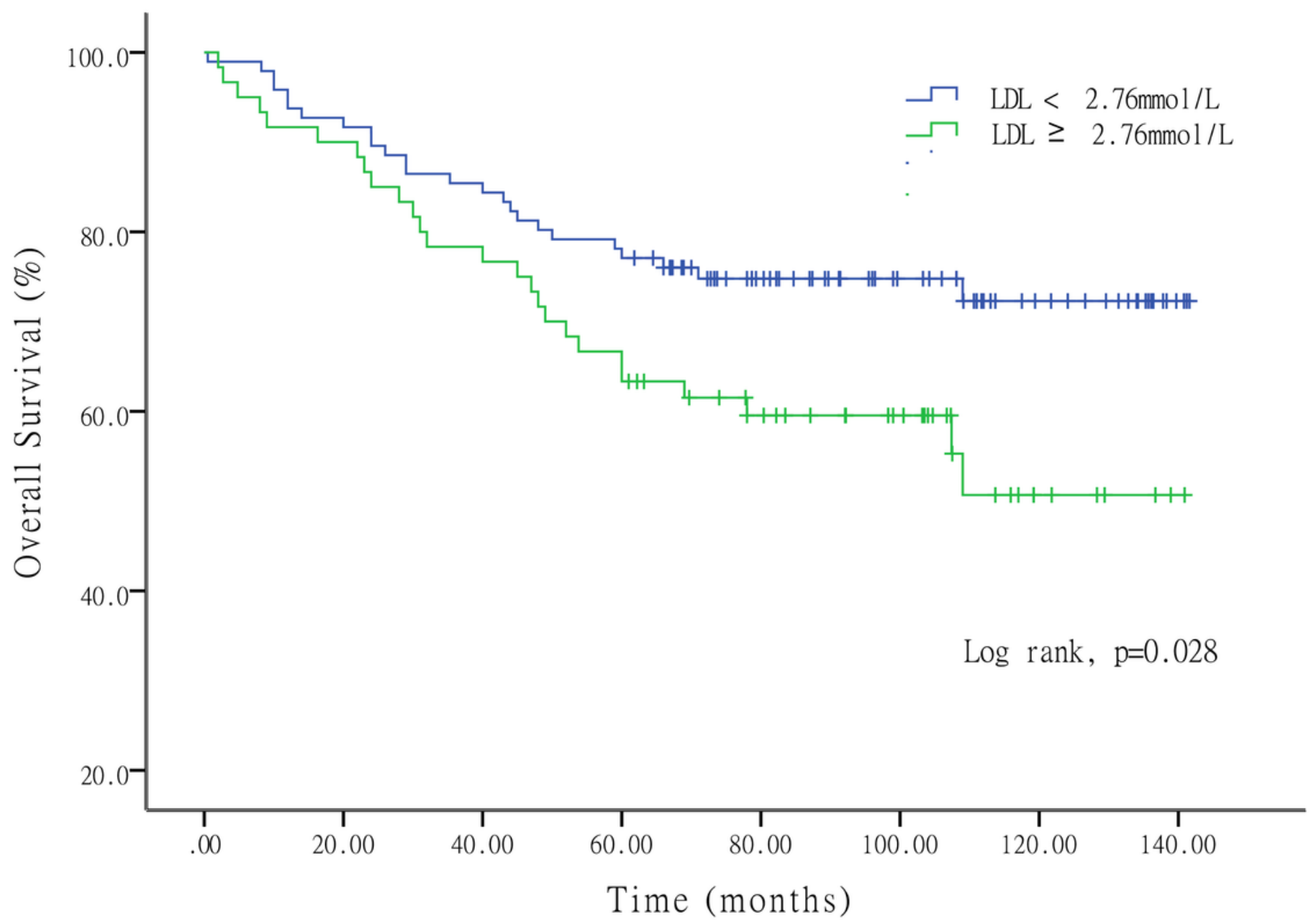

Figure 2

Kaplan-Meier curve of overall survival (OS) according to low vs high LDL-C levels. 